\title{
Estratégias de Diferenciação de Marca para uma Empresa do Setor Químico
}

Brand Differentiation Strategies for a Company in the Chemical Sector

Allan Augusto Platt ${ }^{1}$, Clara Killing Schemes ${ }^{2}$ e Thainá Cruz de Paiva ${ }^{3}$

1,2,3 Universidade Federal de Santa Catarina, UFSC 


\title{
Resumo
}

Este estudo apresenta propostas de estratégias de diferenciação de marca por meio de atributos intangíveis numa empresa do setor químico. São abordados na revisão de literatura os temas diferenciação, valor intangível, branding, branding emocional, propósito e marketing de conteúdo. Além da revisão de literatura, foi realizada uma visita à empresa, em que foi possível entender sua história e as ações da área de Marketing, por meio de entrevistas semiestruturadas com alguns funcionários. Como resultados, foram elaboradas propostas de diferenciação embasadas em exemplos realizados por grandes marcas, que foram divididas em quatro temas centrais: mensagens atrativas e úteis aos olhos dos consumidores; diferenciação por meio de embalagens; experiência do consumidor e diferenciação nas redes sociais. Conclui-se, a partir dos exemplos retratados e das propostas elaboradas é possível se diferenciar por meio de diversas estratégias, sendo elas novas ou até adaptadas de outras empresas e setores e que as marcas necessitam trabalhar aspectos emocionais para alcançar tais diferenciações.

Palavras-chave: estratégias de diferenciação, gestão de marca, valor intangível, branding emocional, marketing

\begin{abstract}
This study presents proposals for brand differentiation strategies through intangible attributes in a company in the chemical sector. The literature review covers the topics of differentiation, intangible value, branding, emotional branding, purpose, and content marketing. In addition to the literature review, a visit to the company was made, in which one can understand its history and the actions of the Marketing area, through semi-structured interviews with some employees. The outcome was the elaboration of differentiation proposals based on examples made by major brands, separated into four central themes: attractive and useful messages to consumers; differentiation through packaging; consumer experience; and differentiation in social networks. It is concluded from the examples portrayed and from the elaborated proposals, it is possible to differentiate through different strategies, being new or even adapted from other companies and sectors, and that brands need to work on emotional aspects to achieve such differentiations.
\end{abstract}

Keywords: differentiation strategies, branding, intangible value, emotional branding, marketing 
Benvenutti (2018) aborda que se vive em um período de abundância, de fartura de opções, escolhas e possibilidades, em que os avanços tecnológicos derrubaram barreiras e transformaram o que era escasso em acessível, tornando produtos e serviços baratos disponíveis a todos e permitindo que o consumidor controle o que consome. Assim, para se destacar no mercado e chamar a atenção do consumidor, a escolha de atributos diferentes de seus rivais é primordial para uma empresa se diferenciar, ser verdadeiramente única em algum aspecto ou ser percebida como tal, se quiser praticar um preço premium (Porter, 1985). Thompson Junior, Strickland III e Gamble (2008) acrescentam que uma maneira de conseguir vantagem competitiva com base na diferenciação está em incorporar fatores intangíveis, que podem estar relacionados ao desejo dos compradores por status, imagem, prestígio, experiência, entre outros. Kotler e Keller (2012) afirmam que o Branding Emocional, uma comunicação de marca com componentes racionais e emocionais pode trazer diferenciação. Ainda segundo os autores, em relação a quesitos emocionais, a autenticidade é um fator muito importante, pois pode evocar confiança, afeto e intensa fidelidade. Já Reiman (2013) aponta que as empresas reconhecidas como autênticas geram resultados emocionais, intelectuais e financeiros, e empresas guiadas por um propósito maior levam as marcas a um conjunto de valores intangíveis, sendo um deles, o amor de seus consumidores.

As organizações do setor industrial, particularmente as com produtos "indiferenciados", ou como Levitt (1980) denomina, "commodities", devem se utilizar do processo de marketing como estratégia de diferenciação. Pereira e Silva (2014) afirmam que no caso das especialidades vendidas ao consumidor final, além da inovação com os produtos, os investimentos em propaganda destinados à valorização das marcas, como no segmento de indústrias químicas, desempenham um importante papel no posicionamento e no sucesso competitivo das empresas. Nessa direção, a indústria química brasileira representou 2,4\% do PIB do país no ano de 2016 e 10,8\% do PIB Industrial no ano de 2015, além de ser a nona colocada no ranking de faturamento líquido mundial, em 2016 (Abiquim, 2017). Nesse setor, a empresa Killing S.A. Tintas e Adesivos, empreendimento familiar com portfólio de aproximadamente 2500 produtos, entre eles tintas, adesivos e solventes, fundada em 1962, é atualmente líder no segmento de adesivos para calçados na América Latina e uma das dez maiores fabricantes de tinta no país (Killing, 2017). Atualmente, a empresa vem passando por mudanças em sua estrutura interna, buscando modernizar-se e reestruturando algumas áreas e processos, incluindo a área de Marketing (Killing, 2017). Neste contexto, Freire Junior (1999) atesta que no mercado de especialidades químicas, tanto empresas em fase de consolidação quanto as já consolidadas encontram dificuldades financeiras ao utilizarem em seus portfólios produtos commodities e pseudocommodities, pois a falta de diferenciação, aliada à influência da globalização, geram uma alta competitividade. Assim, a importância da diferenciação nas organizações, visando chamar a atenção do consumidor, deve cada vez mais ser explorada, sobretudo na incorporação de fatores intangíveis como status, imagem, prestígio e experiência, justificando o objetivo deste estudo que é o de elaborar propostas de diferenciação para a Killing S/A, com base em marcos teóricos e estratégias existentes no mercado, que possam potencializar a aquisição de vantagem competitiva, agregando valores intangíveis à marca. 


\section{Fundamentação Teórica}

Ao não se diferenciar, Aaker (2015) reitera que uma marca corre o risco de entrar na acirrada concorrência de preços, passando a impressão de commodity. Quando isso acontece, a empresa está propensa a ter uma significativa queda em seus lucros, perdendo a vantagem de preço premium que Porter (1985) traz como um dos ganhos da diferenciação. A facilidade de se cair em "comoditização" é causada pelos avanços tecnológicos, que permitem que pequenas marcas criem produtos quase tão bons quanto os de marcas líderes (Rocha \& Ignácio, 2017). Portanto, não basta diferenciar apenas o produto, mas incluir atributos não econômicos ou intangíveis à marca, relacionados ao desejo dos compradores por status, imagem ou prestígio (Thompson Jr., Strickland III \& Gamble, 2008). Kotler e Keller (2012) afirmam que para atingir diferenciação e evitar a armadilha de commodity, a empresa deve criar uma imagem poderosa e atrativa que seus concorrentes tenham dificuldade para se equiparar. Troiano (2016) acredita que as atribuições dadas às marcas são de alta relevância, pois além de ressaltar o diferencial competitivo, ajudam na blindagem das empresas, mostrando sua reputação e as protegendo de eventuais incidentes. Para evitar esse efeito de comoditização, as empresas devem investir em suas marcas relacionando-as às finalidades que acreditam que devam cumprir: aos Sweet Spots de seus clientes, como cita Troiano (2016), pontos ideais de interesses compartilhados entre a marca e eles, pontos importantes que os deixem envolvidos e que os motivem a falar a respeito.

Enfatizando o "boca a boca" promovido por esses interesses compartilhados, Ries e Trout (2009) salientam a importância de um posicionamento de marca, que será o mediador ao fornecer o material para a conversa entre as pessoas, alavancando a relevância da informação passada. Kotler e Keller (2012) trabalham o assunto de posicionamento e gestão de marcas para diferenciação atrelada ao Branding Emocional, ou seja, posicionar as estratégias de marca com componentes racionais e emocionais, de maneira que sua comunicação sensibilize tanto a mente, quanto o coração do consumidor em questão. Para eles, benefícios emocionais são relevantes, pois podem evocar sentimentos de confiança e fidelidade. Para Gobé (2009), o posicionamento de ser visto e sentido também é fundamental, porém não de maneira comum, pois para se obter êxito é necessário criar programas que conectem e engajem os consumidores, com mensagens modulares em situações e lugares diferentes, criando algo atrativo e útil no cotidiano dos consumidores como, por exemplo, as estações de carregadores de celulares da Samsung em aeroportos, peças com design elegante que resolvem um serviço muito necessitado pela população. Gobé (2009) comenta também que o Branding Emocional é aquele atrelado a fatores mais humanos, movido por emoções que envolvem e influenciam as pessoas de dentro e de fora da organização. $\mathrm{O}$ autor explica ainda que quando uma marca interage com seus clientes em um nível emocional, a mesma ganha vida para os consumidores, criando uma relação profunda e duradoura.

Aaker (2015) e Rocha e Ignácio (2017) conceituam identidade de marca como a soma de todos os seus componentes tangíveis e intangíveis, sendo eles benefícios funcionais, emocionais e de autoexpressão. A respeito de benefícios emocionais, Rocha e Ignácio (2017) descrevem alguns sentimentos dos consumidores no momento de se relacionar ao produto, como o prazer ao dirigir um carro BMW, o status ao usar um relógio Rolex, ou até a 
irreverência e descontração de usar sandálias Havaianas. Aaker (2015) traz um estudo de segmento que por meio de testes padronizados descobriu que quarente e sete comerciais de TV que possuíam benefícios emocionais atingiam resultados significativamente maiores de eficiência do que 121 comerciais que só exibiam benefícios funcionais. Transcender os benefícios funcionais pode auxiliar a marca a criar barreiras, uma vez que eles são facilmente copiados e que é muito mais difícil copiar benefícios emocionais, valores e a cultura da organização ou até a personalidade da marca (Aaker, 2015). Uma forma de evocar benefícios emocionais, segundo Gobé (2009), se dá por meio de marcas com elementos surpresa em suas campanhas, pois têm maiores chances de criar um impacto emocional e um elo com o consumidor. Ainda, cita a campanha da Vodka Absolut (Figura 1) com diversos outdoors 3D, como uma garrafa excedendo quatro metros de altura em Los Angeles, onde diversos artistas jogavam diariamente várias camadas de tinta, e os apartamentos na vertical que compunham o formato da garrafa da marca em Nova York, chamando a atenção de todos que passavam pelo local.

Figura 1.

Outdoor da marca Absolut, em Nova York.

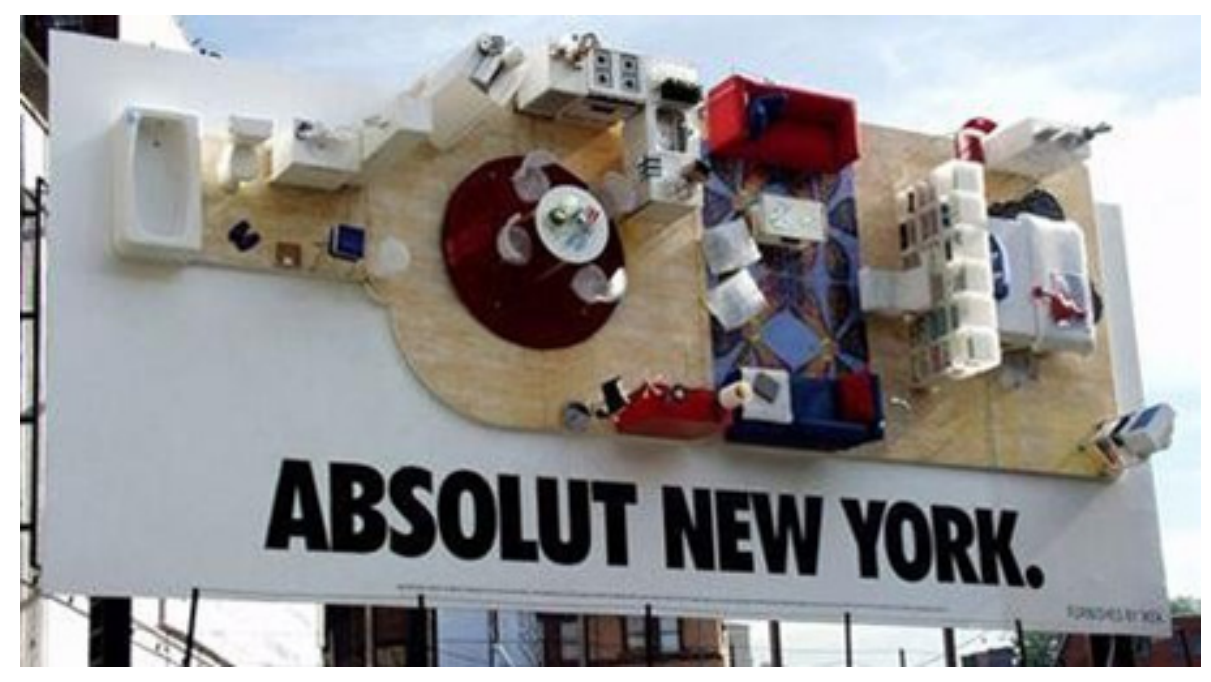

Nota. Flickr, n.d.

Rocha e Ignácio (2017) alertam que dentro de um mesmo segmento de mercado as percepções de experiência do consumidor, muitas vezes, serão diferentes, o que torna a oferta de valor complexa, pois ao oferecer benefícios demais, querendo atingir todos do segmento, a marca acaba confundindo seu real público-alvo sobre sua verdadeira proposta de valor. Ainda, ressaltam o fator concorrência, pois toda vez que benefícios tangíveis são oferecidos, há grandes chances de os mesmos serem copiados, transformando o que um dia foi diferencial num padrão. Para que isso não ocorra, os gestores de marcas necessitam fugir do senso comum e entregar benefícios além da concorrência. Fugir do senso comum e do excesso de postagens nas redes sociais pode ser algo complexo, mas quando se expõe e compartilha emoções na internet em um nível mais pessoal, se cria uma oportunidade ao construir um caminho inteligente para ganhar a confiança e credibilidade dos consumidores, numa relação de "coração para coração", oportunizando as empresas compartilharem seus valores com seus consumidores (Gobé, 2009). Superti (2019) corrobora com a ideia de que as marcas devem fugir de benefícios tangíveis, apresentando a 
pirâmide do valor agregado (Figura 2). Na base encontram-se as marcas que vendem apenas "funções", e acabam na posição de maior concorrência, pois não conseguem se diferenciar.

Figura 2.

Pirâmide do valor agregado

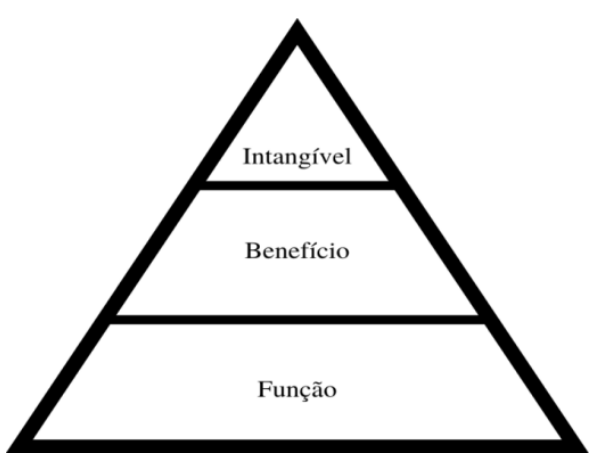

Nota. Superti, “Fator X Live”, 2019.

Acima dessas marcas, encontram-se as que vendem "benefícios", que apesar de conseguirem apresentar pontos com diferenciais, apresentam-nos de maneira tangível e copiável (Superti, 2019). Um exemplo de venda de benefícios seria um carro automático e com direção hidráulica. As poucas marcas que conseguem realmente se diferenciar são aquelas que alcançam o intangível, ou seja, que não vendem somente carros, vendem um estilo de vida, como Rolls-Royce, Audi e Ferrari (Superti, 2019). Aaker (2015) alega que pesquisas sobre caminhonetes, por exemplo, sugerem que atributos racionais como durabilidade e recursos de segurança são considerados os mais importantes pelos clientes. No entanto, os atributos mais intangíveis como "aparência legal", ser "divertido de dirigir" e "sensação de poder" têm maior probabilidade de influenciar os clientes, que, muitas vezes, não admitem que esses atributos supostamente supérfluos, são importantes. Ainda de acordo com o autor, na maioria dos casos, os clientes não têm motivação, tempo, informações ou competência para tomar decisões que maximizem resultados de desempenho e então projetam benefícios funcionais a partir de outras associações de marca. Tendo os benefícios emocionais/intangíveis, cria-se o poder de agregar riqueza, profundidade à marca e proporcionar a experiência de possuí-la e utilizá-la. Componentes intangíveis, além de difíceis de serem mensurados, têm também maior possibilidade de serem diferenciados. Para Rocha e Ignácio (2017), são atributos relacionados à forma simbólica e emocional de uma marca, corroborando a visão de Kotler e Keller (2012), de que são emoções proporcionadas ao consumidor ao se relacionar com uma marca.

Uma vez que uma marca conquista um consumidor por meio de características intangíveis, uma conexão se forma de maneira tão profunda que se atinge a fidelidade de marca, um dos ativos mais importantes que uma marca pode conquistar, como aborda Aaker (2015). O autor afirma que romper um elo de fidelidade é, além de difícil, muito caro para a concorrência. Quando conquistada essa conexão e fidelidade em que um consumidor identifica determinada característica e sua mente o direciona para determinada marca, como o aroma do café da Starbucks, o ronco do motor de uma Harley- Davidson ou o vermelho em uma caixa de cigarros, associado à Marlboro, estas marcas conseguiram convencer seus consumidores de seus diferenciais (Rocha \& Ignácio, 2017). 
Para Reiman (2013), uma maneira de alcançar diferenciação com valores intangíveis de marca é por meio do quesito propósito. Marcas que possuem um propósito único e autêntico têm poder maior de atrair consumidores, pois as pessoas são naturalmente envolvidas e mobilizadas por histórias e causas, sendo o desafio conseguir encontrar um propósito que consiga se conectar de verdade aos seus consumidores, sem que a marca perca sua cultura, essência e valores (Rocha \& Ignácio, 2017). Como primeiro passo para identificação de seu propósito, os autores sugerem que as empresas se perguntem o que o mundo perderia se elas deixassem de existir. Para Benvenutti (2018) quando se tem um propósito claro, gera-se algo muito mais profundo, levando tanto seus consumidores, quanto colaboradores e investidores a acreditarem no que a empresa acredita, sonhar o que a empresa sonha e amar o que a empresa ama, sendo isso, um elemento intangível capaz de movimentar a organização como um todo. Rocha e Ignácio (2017), por sua vez, acreditam que propósito vai além dos tradicionais atributos que uma marca carrega, tendo como principal fator as causas para qual contribuem. Aaker (2015) acrescenta que propósito pode ser visto como um "item obrigatório", podendo se tornar a base para o sweet spot do consumidor, sendo algo que vai além da oferta, tal como a Pampers faz, com o site Pampers Village que dá dicas de cuidados com bebês; ou como a paixão demonstrada pela Whole Foods Market por alimentos orgânicos e saudáveis. Reiman (2013) relaciona propósito ao terceiro W dos "3W's": who (quem), what (o quê), why (por quê), afirmando que apesar de no passado ser suficiente saber apenas para "quem" e "o quê" se está vendendo, hoje os consumidores querem sabem o "por quê" por trás das ações da marca.

Uma forma de mostrar aos consumidores o "por quê" por trás de suas ações, o seu propósito ou no que a empresa acredita, está no posicionamento por meio de uma narrativa ou história, o storytelling, uma narrativa com base em metáforas que possam se conectar com os consumidores baseadas em memórias, associações e a história das pessoas (Kotler \& Keller, 2012). Os autores explicam ainda que a estratégia de contar histórias educa, entretém, envolve e ainda cria um impacto sobre o público consumidor, pois o conteúdo vai além das propostas de função e benefício de produto ou serviço, passando a transmitir a razão pela qual a organização existe. Uma maneira de contar histórias, se diferenciar e alcançar aspectos emocionais dos consumidores se dá por meio de embalagens, estratégia muito usada por marcas de perfumes (Gobé, 2009). Superti e Den (2019) afirmam que a embalagem tem o poder de contar a história de como seu produto foi criado, qual sua visão de mundo e como as coisas acontecem na sua empresa em segundos. Eles citam as famosas caixinhas azuis de jóias da marca Tiffany \& Co., que se tornaram um objeto de desejo quase maior que a própria joia, assim como as caixinhas de suco infantil Birdy Juice que, de maneira criativa, conversam com seu público alvo e ainda possuem benefício multifuncional, podendo ser também um brinquedo. Ao criar conteúdos com histórias envolventes e relevantes aos consumidores, as marcas conquistam a desejada posição de "vender, sem vender" (Pulizzi, 2016). Kotler, Kartajaya e Setiawan (2017) acrescentam que um bom marketing de conteúdo é aquele que apresenta informações de alta qualidade e que beneficie os consumidores a alcançar objetivos pessoais e profissionais, mesmo que isso não contribua diretamente para o valor de marca, nem melhore o volume de vendas. Os autores ressaltam a importância em transmitir conteúdos com um lado humano, acessível, amável, vulnerável, autêntico e honesto, admitindo inclusive 
suas falhas, caso necessário. As marcas movidas por valores básicos, centradas no ser humano, conseguem criar laços de amizade com o consumidor, podendo ser a chave para diferenciação na era digital de informações em excesso. (Kotler, Kartajaya \& Setiawan, 2017). A vantagem do marketing de conteúdo, na visão de Gobé (2009), se dá pela diferenciação do marketing de massa, que foca em postar excesso de informações, muitas vezes irritando o público-alvo com mensagens insistentes e indesejadas. Aaker (2015), também ressalta que criar conteúdos que se conectem aos sweet spots dos clientes ajudam a marca a se destacar e a se concretizar em tempos de overdose de mídias sociais. Gobé (2009) ainda relaciona que ser conhecido não significa ser amado, portanto se a marca deseja conquistar o amor de seus clientes, deve encontrar algo que convenha com as aspirações dos mesmos, pois os consumidores pensam mais com seus corações do que com suas cabeças na hora de decidir uma compra.

\section{Metodologia}

A natureza desta pesquisa é descritiva aplicada, em que se busca analisar estratégias e propor possíveis soluções para que a empresa estudada alcance a diferenciação de marca, por meio de atributos intangíveis. A abordagem da pesquisa é de caráter qualitativo contendo dados primários e secundários, em que foram utilizadas fontes bibliográficas como referência, documentos fornecidos pela organização e o método de observação simples e entrevistas semiestruturadas e focalizadas conforme Gil (2008), para descrição do estudo.

Para a realização da pesquisa, os autores passaram três dias integrados à rotina da empresa, em especial, junto aos colaboradores dos setores de gestão de pessoas, marketing e segurança do trabalho. Para as observações durante o período de inserção na empresa elaborou-se um roteiro, no qual se buscou conhecer melhor o ambiente organizacional e, além disso, a história de constituição e fortalecimento tanto da empresa quanto da sua marca. A observação ocorreu durante o mês de julho de 2019. Também foram realizadas três entrevistas: uma com o presidente da empresa, outra com o diretor comercial e de marketing e mais uma com o gerente de marketing e de produção. As entrevistas semiestruturadas abordaram assuntos como a trajetória da empresa, rotina de trabalho, estratégias utilizadas, desafios a serem superados e posicionamento de marca, sempre com foco nas atividades voltadas ao marketing.

Para análise dos dados, foram feitas análises bibliográficas, ancoradas em casos de benchmarking para a elaboração das propostas de diferenciação, bem como análise dos documentos fornecidos durante a observação e entrevistas realizadas durante a inserção na Killing S.A.

\section{A Empresa e o Marketing}

Fundada em 1962, na cidade de Novo Hamburgo, Rio Grande do Sul, onde está sua sede até hoje, pelo empreendedor Leopoldo Celestino Killing, a Killing S.A. Tintas e Adesivos surgiu quando seu fundador, na época atuando como pintor, recebeu uma proposta de um de seus clientes que lhe ofereceu uma fábrica de tintas para couro e solados, com apenas algumas fórmulas, poucos equipamentos e um funcionário, por um preço extremamente acessível (Killing, 2017). Celestino enxergou na proposta uma grande oportunidade e realizou a compra vislumbrando o crescimento do mercado calçadista da região (Killing, 2017). Com 57 anos de história, a Killing, que começou em um ateliê no fundo de um quintal, tornou-se líder no segmento de adesivos da América 
Latina e uma das dez maiores empresas no segmento de Tintas Imobiliárias e Industriais (Killing, 2017). Além da matriz em Novo Hamburgo, tem quatro filiais: uma em Simões Filho na Bahia, uma em Buenos Aires, na Argentina, uma na Cidade do México, e a última em Curitiba, no Paraná e está dividida em duas unidades de negócio: Adesivos e Tintas (Killing, 2017). Ainda, segundo o site da empresa, a unidade de Adesivos é lider de mercado na América Latina com $60,27 \%$ do faturamento total da empresa, fornecendo matéria-prima para indústrias calçadistas e moveleiras, além de atuar em revendas especializadas do mesmo segmento. Já a unidade de Tintas é subdividida entre Tintas Industriais e Tintas Imobiliárias. A primeira atende a segmentos de implementos rodoviários, como máquinas agrícolas, ônibus, caminhões, além de indústrias moveleiras e segmentos de acabamentos para couro; a segunda subdivisão, mais popular entre os consumidores finais, comercializa tintas, vernizes, massas e texturas para revendas, como lojas de materiais de construção, ferragens, home centers e construtoras (Killing, 2017).

Durante a entrevista com o presidente da empresa, foi possível evidenciar que a empresa possui como desafio a característica de suas vendas serem extremamente técnicas em ambas as unidades. Já a conversa com o diretor comercial e de marketing esclareceu que nas vendas para outras empresas há o benefício do comprador ser qualificado e entender das especificidades do produto, já naquelas feitas ao consumidor final, os clientes costumam levar em consideração a opinião dos especificadores (balconista, pintor, arquiteto) para a tomada de decisão. Além disso, buscam a familiaridade com a marca em questão, pois na falta do conhecimento técnico, as pessoas costumam procurar por algo que Ihes é familiar.

Com o objetivo de melhorar sua performance na unidade de negócios de Tintas, a empresa traçou como estratégia de marketing focar no estado da matriz, onde a marca possui mais força (Entrevista com o diretor comercial e de marketing). Tal estratégia corrobora com as ideias de Ries e Trout (2009), de que quando se possui uma determinada quantia de orçamento, é mais adequado gastar mais em uma única região do que gastar menos em várias, pois se alcançar sucesso nesse único território, a estratégia pode se estender para outros no futuro. 0 diretor comercial e de marketing explicou ainda, que para viabilizar essa estratégia, decidiu-se por estruturar sua área de Marketing, contratando um gerente e um especialista em inteligência de mercado. $O$ diretor ressaltou que, anteriormente a área era composta por apenas quatro colaboradores, responsáveis pelo design de embalagens de mais de dois mil e quinhentos produtos, participação em feiras e prestação de assessoria a empresas terceirizadas para realização da publicidade e comunicação externa. Antes da percepção de mudança, as ações de marketing da Killing constituíam-se em comunicação de produto pelas redes sociais, outdoors, trade marketing nos pontos de venda, pinturas de estádios de futebol, como o do Grêmio, do Internacional, do Avaí, da Chapecoense, entre outros (Entrevista com o diretor comercial e de marketing. A empresa também realizou ações diferenciadas, como a campanha do "Homem Amarelo" pela cidade de Porto Alegre e a pintura da faixa de pedestres de rosa do Hospital Santa Casa de Misericórdia para a campanha Outubro Rosa, abraçando a causa do câncer de mama (Entrevista com o diretor comercial e de marketing), conforme a Figura 3. 
Figura 3.

Ações de marketing da Killing.

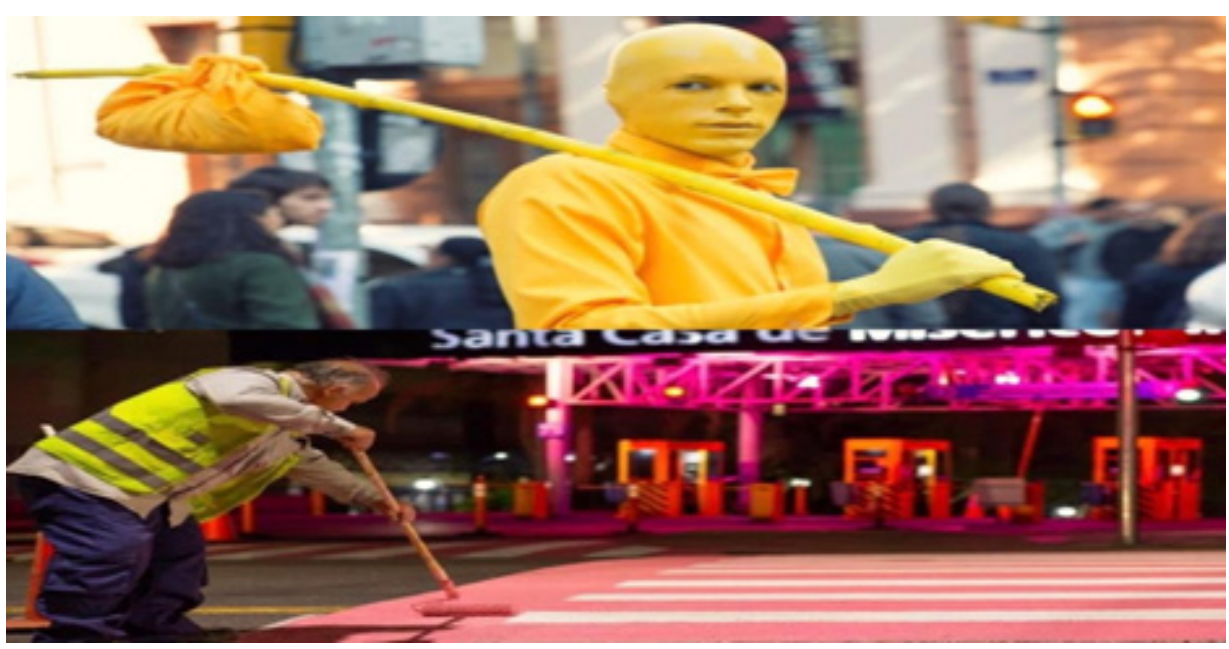

Nota. Montagem a partir do site da Killing, 2019.

Além dessas ações de marketing, a empresa tem promovido o evento beneficente "Meio Frango -

Simplesmente Juntos", em que os funcionários e familiares se voluntariam para preparação de frangos assados e toda a verba das vendas é revertida para instituições de caridade, além da doação de tintas para restauração de edifícios abandonados e escolas (Entrevista gerente de marketing).

Ainda de acordo com o gerente de marketing, apesar de possuir ações diferenciadas, com propósito e que conversem com o público, algumas das ações poderiam ter alcançado maior reconhecimento, explorando melhor a marca, como no exemplo da faixa de pedestres, em que em nenhum lugar o nome Killing ficou exposto, além da pouca divulgação pela imprensa local. O gerente de marketing complementa sua posição ao dizer que essas ações poderiam ter gerado resultados positivos para empresa se o público pudesse reconhecer a marca em algum momento durante a ação, algo simples, como no uniforme do homem pintando a faixa, por exemplo, demonstrando que a Killing apoia e abraça esse tipo de causa de forma sutil.

\section{Propostas de Diferenciação}

Conectando o marco teórico e exemplos apresentados com o cenário de marketing da empresa em questão, somados à situação de mudanças e crescimento pela qual a mesma está inserida, são propostas alternativas de ações, embasadas em benchmark que possam vir a resultar em valores intangíveis de marca para a Killing. Com eles, a empresa poderá atrair a atenção e até conquistar o coração de seus consumidores.

\section{Mensagens atrativas e úteis aos olhos dos consumidores}

A partir das premissas de Gobé (2009) de que as marcas precisam criar mensagens atrativas e úteis no cotidiano dos consumidores, como o exemplo dos outdoors da vodca Absolut, e como o das estações de carregadores de celular da Samsung em aeroportos, a Killing poderia usar do poder das cores para "pintar" situações criativas. Poderia concretizá-las por meio de outdoors interativos e parcerias com artistas que, segundo Díaz e Martin (2016), foi a estratégia que elevou a vodca Absolut a um nível artístico, sendo este um atributo intangível que vai além apenas do produto. Essa estratégia pode ser unida ao humor, levando aspectos que deixem o dia a dia dos seus consumidores alvo mais leve e colorido, seja no caminho para o trabalho, no trânsito ou até em 
momentos de lazer. Gobé (2009) explica que quando se consegue fazer alguém rir, há maior probabilidade de uma relação amigável com esta pessoa e dela lembrar no futuro do causador do riso.

Como citado anteriormente, a empresa já utilizou a estratégia de propor situações criativas e úteis no dia a dia do consumidor, como a do Homem Amarelo e a faixa de pedestres cor-de-rosa, com o objetivo de conscientizar a população sobre uma causa. Tais ações podem ser revitalizadas e voltarem a serem trabalhadas pelas empresas. Uma forma de revitalização da campanha do Homem Amarelo seria tanto aplicá-la em novas cidades, quanto utilizar a ideia em novas cores e com mais pessoas, criando um grupo que forme as cores do logo da empresa (amarelo, azul e alaranjado), por exemplo. Outra forma de inovar essa campanha seria substituir o Homem Amarelo por um tucano, símbolo da empresa.

A campanha da faixa de pedestres cor-de-rosa, por sua vez, pode ser incorporada por novos hospitais e mudar de cor a cada mês, conforme a cor da causa. Em setembro pode ser amarela, para a campanha de prevenção ao suicídio; em outubro cor-de-rosa, para a campanha de prevenção do câncer de mama e em novembro azul, para a campanha de prevenção do câncer de próstata. Outra maneira de revitalizar a campanha, lembrando sempre de evidenciar a marca, seria incorporando a arte no design dessas pinturas, fugindo do convencional e criando situações "instagrameáveis", mais precisamente, situações em que as pessoas sentem a necessidade de bater uma foto e compartilhar nas redes sociais, como evidencia a Figura 4.

Figura 4.

Inspirações para faixa de pedestres

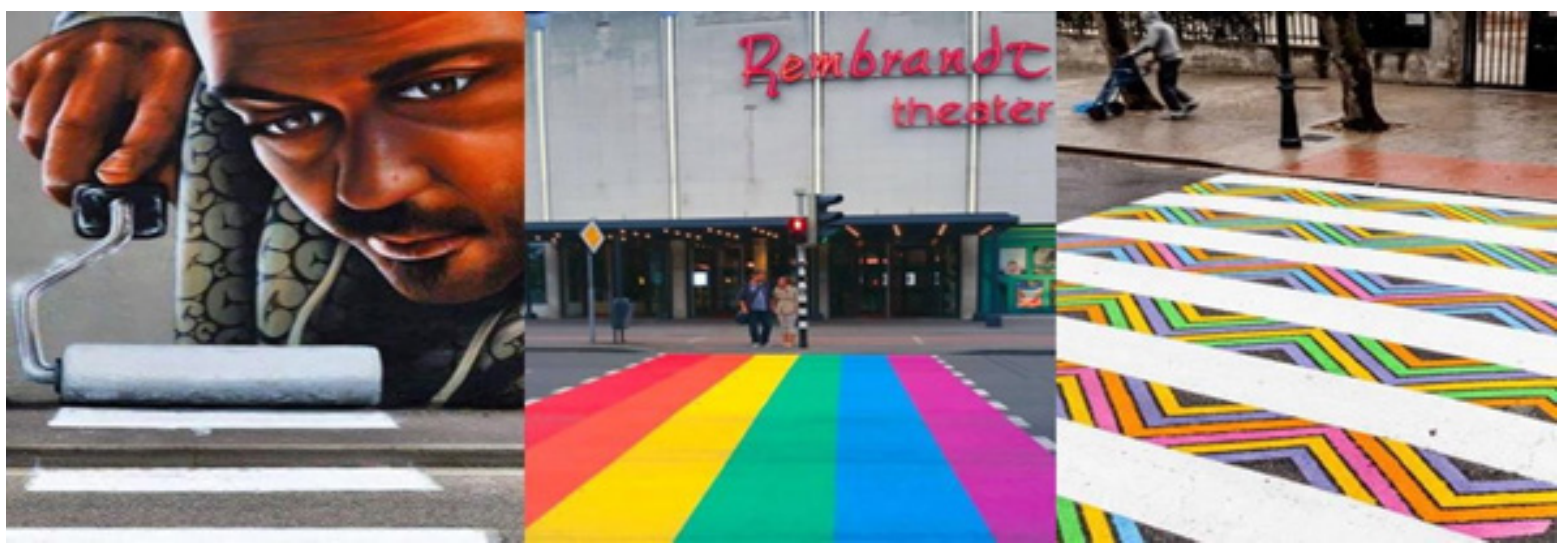

Nota. Montagem a partir dos sites Catraca Livre (2015), Robbie (2018) e Fontes (n.d.).

\section{Diferenciação por meio de embalagens}

Segundo o estudo Packaging Matters da Meadwestvaco Corporation (2015), o poder das embalagens citado por Gobé (2009), Superti e Den (2019) não pode passar despercebido, apontando que $60 \%$ dos consumidores brasileiros acreditam que a embalagem é um relevante fator de satisfação e $20 \%$ se tornaram fãs de uma marca por causa da embalagem. Levando em consideração a versatilidade que uma lata de tinta pode ter devido a seu tamanho e formato, a Killing, que apesar de precisar utilizar boa parte do espaço para especificações técnicas de produto, pode aproveitar o uso de embalagens para intensificar seu posicionamento e gerar valores intangíveis de marca. Utilizando o exemplo dos sucos Birdy Juice (Superti \& Den, 2019), a empresa poderia criar uma embalagem 
de tintas versão infantil, reforçando seu cuidado pela saúde e pela família do consumidor, com produtos à base de água e que possa se tornar reutilizável depois pelos pais, como uma lata que se torna um porta-brinquedos.

Outra maneira possível de se aproveitar os benefícios das embalagens, segundo Superti e Den (2019) e Gobé (2009), é a de contar histórias: como o seu produto foi criado, como sua empresa foi fundada e qual sua visão de mundo. Desta maneira, a empresa poderá intensificar sua posição como marca gaúcha, brasileira e explorará a história de seu fundador, que iniciou a carreira como um pintor com poucos recursos e conseguiu transformar a Killing em uma empresa líder da América Latina. Segundo Aaker (2015), o ato de contar a tradição de um fundador ou o que estabeleceu a essência da marca pode ser um fator importante na comunicação e inspiração de seus consumidores. Contar histórias sobre as raízes da marca tende a ser uma experiência rica e relevante, destacando a marca entre outros produtos. $\mathrm{O}$ autor reforça, ainda, que a marca pode alcançar enorme credibilidade ao se atrelar a uma cultura. Entretanto, não se pode esquecer, no caso da Killing, uma empresa internacional, essa estratégia deve ser cuidadosamente analisada, já que o que funciona para uma região, não necessariamente irá funcionar para outra. Para ressaltar a cultura regional dentro das embalagens, é possível criar nomes e layouts para tintas remetendo a símbolos considerados tradicionalmente gaúchos, como por exemplo: "verde erva mate", "laranja bergamota", "marrom acampamento farroupilha", "branco chimango", dentre outras diversas possibilidades.

\section{Experiência do consumidor}

Mais uma forma de conquistar a mente e o coração dos consumidores é por meio de uma experiência diferenciada, por meio do layout das lojas. Rocha e Ignácio (2017) trazem o exemplo das lojas da Apple, que segundo a Forbes Brasil (2019) e a Interbrand (2019), é a marca mais valiosa do mundo. A marca possui lojas com um layout limpo, onde não há caixas para o pagamento, nem departamento de embalagem, buscando destacar seus produtos. Há apenas os vendedores, que se destacam pelo vasto conhecimento sobre a marca e principalmente sobre os produtos. A Killing poderia apostar nessa mesma estratégia para chamar a atenção dos clientes, afinal, uma loja livre de distrações onde o foco é o produto, o vendedor e especificador da venda, que entende e sabe indicar a melhor opção para a necessidade do cliente, pode ser uma grande alternativa. 0 cliente se sente especial e passa a criar empatia pela marca e os atributos que ela entrega, além da qualidade do produto. Vale a pena ressaltar que para essa estratégia ter seus resultados é necessário voltar sua atenção para os vendedores também, que precisam se sentir especiais e valorizados pela empresa, além dos treinamentos para que estejam capacitados a transmitir aos clientes todo e qualquer conhecimento sobre o produto e sobre a marca.

Para aprimorar os eventos que já são desenvolvidos pela Killing, é possível agregar também a experiência. Nesse quesito, Rocha e Ignácio (2017), enfatizam a empresa Red Bull, que realiza eventos com o objetivo de construir experiências vinculadas à marca. O Red Bull Stratos, evento realizado pela marca, transmitiu ao vivo pelo site da empresa um paraquedista que fez um salto da estratosfera. A transmissão do evento gerou 8 milhões de visualizações ao vivo, além de toda a exposição global gerada pela ousadia da ação. O tamanho da exposição pode ser atribuído a dezenas de milhares de dólares, devido ao seu alcance, e permitiu a marca enfatizar seu posicionamento e seu famoso slogan "Red Bull te dá asas" (Forbes, 2012). Ao buscar esse aprimoramento, a Killing 
poderia realizar mais eventos para integrar a comunidade e os consumidores de forma mais experiencial, como visitas à fábricas abertas ao público para entender como funciona o processo de produção das tintas e adesivos; promover minicursos para balconistas, pintores e arquitetos e para a população em geral; convocar a comunidade para eventos beneficentes que a Killing já apoia e "patrocina", como doar tintas para pintar escolas, com um convite para que a população regional ajude a pintá-las, por exemplo, entre outras opções. Dentro da categoria de eventos beneficentes, a empresa já possui o evento "Meio Frango - Simplesmente Juntos", citado anteriormente, que envolve desde seus colaboradores, à família dos mesmos e voluntários externos em prol de uma causa. O “Meio Frango" está mais relacionado ao propósito da empresa em ajudar, do que necessariamente às funções que a mesmo executa, o que torna a causa mais genuína aos olhos do consumidor.

Outra causa que a empresa poderia abraçar é a da sustentabilidade, podendo convidar seus consumidores para um dia de caminhada pelas praias do sul do estado da matriz, com o intuito de recolher resíduos poluentes em prol do meio ambiente, por exemplo. Toda a ação poderá ser feita com as pessoas uniformizadas de camisetas e bonés com o nome e logo da empresa e filmada por drones ao longo da costa. A ação não apenas geraria material para a empresa divulgar em suas redes sociais, como se conectaria aos seus clientes que abraçam a causa. Além disso, todos os resíduos recolhidos poderiam ser doados a cooperativas que possam reciclá-los e devolvê-los à cadeia de produção, ajudando não só o meio ambiente, mas também pessoas das cooperativas, que estariam se beneficiando financeiramente com a venda desses resíduos.

\section{Diferenciação nas redes sociais}

Explorar as redes sociais de maneira intangível é o que diferencia marcas em tempos de excesso de postagens que não agregam nada ou muito pouco à vida do consumidor. Analisando a pirâmide de valor agregado (Imagem 2) trazida por Superti (2019), fica claro que as empresas que vendem funções, ou seja, produto, ficam na posição de maior concorrência, correndo maiores riscos de se tornarem commodities. Nas redes sociais, isso não é diferente. Uma empresa que realiza isso com maestria é a Netflix que segundo Melo (2019), se comunica de forma humanizada, com humor, sarcasmo e carinho, utilizando a linguagem dos internautas e se colocando em uma posição horizontal de convivência, com o objetivo de se mostrar capaz de entender seus clientes de igual para igual. A Netflix, de acordo com a Forbes Brasil (2018), possuía mais de 48 milhões de usuários ao redor do mundo já em 2014. A Killing, dessa forma, poderia explorar mais a sua comunicação online com mensagens com significado, atendendo às necessidades dos consumidores, com informações valiosas e convincentes para os mesmos, como sugere Pulizzi (2016). Essas informações devem beneficiar os consumidores a alcançar objetivos pessoais e profissionais, mesmo que isso não contribua diretamente para o valor de marca e nem melhore o volume de vendas (Kotler, Kartajaya \& Setiawan, 2017). Uma maneira de a empresa incorporar essa proposta poderia ser criando tutoriais úteis de como utilizar seus produtos de forma prática e eficiente, ensinando, inclusive, a forma correta de como descartá-los para não prejudicar o meio ambiente ou formas de se reutilizar as embalagens para outros meios, como transformar os galões de tintas em vasos ou bancos. 
Outra opção, ainda, seria apresentar maneiras criativas de transformar ambientes utilizando as cores produzidas pela empresa. Apresentar tendência de cores da próxima estação ou quais cores são escolhas certeiras para se utilizar no ramo dos negócios, em ambientes acadêmicos ou em lugares com mais descontração. Mostrar aos clientes como as paletas de cores podem influenciar no humor das pessoas, por meio de comunicação interativa, com posts informativos, vídeos e tutoriais, para gerar interesse dos clientes pelos conteúdos que a Killing fornece. Também é possível postar vídeos com depoimentos, apostando nas histórias clássicas abordadas por Aaker (2015), com pessoas pertencentes à família Killing, por exemplo, contando como a fábrica começou ou como foi viver parte de sua infância "dentro" de uma fábrica como a Killing, além de relatos de funcionários falando sobre suas trajetórias dentro da empresa e até de clientes contando sobre sua experiência com a Killing. Acredita-se que além de atrair a atenção dos consumidores online por meio de mensagens com significado, é interessante explorar a interação com os mesmos nos comentários, tirar dúvidas e publicar feedbacks para que os clientes se sintam importantes e para enfatizar a credibilidade da marca. Criar histórias no Instagram é uma forma de interagir com o público por meio de caixas de perguntas, pois clientes poderão tirar suas dúvidas e fazer perguntas que serão respondidas pela empresa. Esse trabalho poderá ser assumido pelo CEO da empresa, uma vez por mês, tornando essa ação de interação diferenciada, mais uma vez, fazendo com que os clientes se sintam especiais e valorizados.

Retoma-se que as propostas ora apresentadas estão ancoradas na teoria do marketing com foco na valorização do cliente e, sobretudo, no mercado que a Killing S/A abrange e na cultura organizacional da empresa, elementos essenciais para a construção de estratégias de inserção e venda de produtos. Assim, findadas as discussões, na sequência, apresentamos as considereções finais.

\section{Considerações Finais}

O objetivo deste estudo foi o de analisar estratégias de se diferenciar no mercado e propor para a Killing S/A formas de fugir da comoditização, agregando atributos intangíveis à sua marca e gerando vantagem competitiva. Para atingir tal objetivo foi analisada a literatura sobre diferenciação com exemplos de sucesso, além de uma breve inserção na sede da empresa com a realização de entrevistas semiestruturadas que permitiram conhecer a realidade da empresa.

Foi constatado que marcas necessitam trabalhar aspectos emocionais, ou seja, questões intangíveis, para alcançar a diferenciação. Marcas que criam conteúdos abordando tais aspectos alcançam maior êxito, tanto em termos de reconhecimento, fidelidade e amor, quanto em termos financeiros, que se tornam uma consequência dos anteriores. Conquistar a fidelidade e amor dos clientes, além de importante para sua diferenciação dentre os demais, é essencial para sua perpetuação no mercado. A partir dessas premissas foram elaboradas propostas divididas em quatro temas principais referentes às mensagens, em que o foco é possibilitar estratégias para que o cliente identifique e reconheça a marca; às embalagens, em que o foco são as inúmeras formas de usá-las para encantar o público; às experiências, ações para que o consumidor possa se conectar com a marca e às redes sociais, em que o foco está em como criar conteúdo que gere interesse e engajamento. 
Constatou-se que ideias de diferentes setores correlacionadas à literatura sobre o tema podem ser adaptadas para novas realidades e produtos, direcionando diversos tipos de negócios a se diferenciar por meio de atributos intangíveis. Também se percebeu o quão importante é discorrer sobre diferenciação, principalmente na atualidade, em que tudo é passível de concorrência, ficando evidente que é exequível se diferenciar independente do setor. Cabe a Killing, entretanto, bem como a outras empresas, usar e se inspirar nas propostas e ideias aqui apresentadas e adaptá-las conforme sua realidade, seja ela setorial, estrutural ou orçamentária.

As limitações do estudo caracterizam-se pela falta de aplicação das propostas dentro da empresa estudada, por se tratar de uma pesquisa que se baseia diretamente em uma correlação com o marco teórico apresentado. Sendo assim, embora os fundamentos apontem que seja possível, não se pode garantir que a implantação das propostas e os resultados que poderão ser obtidos serão os mesmos que foram para as empresas citadas.

Sugere-se, para estudos posteriores, analisar quais dessas propostas de estratégias de diferenciação foram implementadas pela Killing e quais resultados foram obtidos. Pode-se também aplicar em outras empresas de outros setores em que seus produtos também são comodities para averiguar e comparar resultados. 


\section{Referências}

Aaker, D. (2015). On branding: 20 princípios que decidem o sucesso das marcas. Porto Alegre: Bookman.

Abiquim (2017). O desempenho da indústria química em 2017. Recuperado em 10 de abril de 2019, de https:// www.abiquim.org.br/uploads/guias_estudos/desempenho_industria_quimica_2017.pdf

Badenhausen, K. (2019). As 100 marcas mais valiosas do mundo. Forbes. Recuperado em 06 de outubro de 2019 de, https://forbes.com.br/listas/2019/05/as-100-marcas-mais-valiosas-do-mundo-em-2019

Benvenutti, M. (2018) Audaz: as 5 competências para construir carreiras e negócios inabaláveis nos dias de hoje. São Paulo: Editora Gente.

Catraca Livre (2015). Artista transforma faixa de pedestre em arte urbana. Recuperado em 09 de outubro de 2019 de, https://catracalivre.com.br/criatividade/artista-transforma-faixa-de-pedestre-em-arteurbana/

Díaz, O.H.; Martín, M. Á. C. (2016). El arte en la publicidad. Tipologías del uso del arte visual en la comunicación comercial. Comunicación y Medios, [s.I.], n. 34, p.96-113. Universidad de Chile. Recuperado em 09 de outubro de 2019 de, https://revistaderechoambiental.uchile.cl/ index.php/RCM/ article/view/42715

Freire Júnior, J. L. A. (1999). Análise estratégica para as novas empresas químicas de especialidades: Uma proposição inicial formada a partir da análise de conceitos de diferentes escolas estratégicas. Dissertação (Mestrado), Fundação Getúlio Vargas. São Paulo

Fontes, M. (n.d.). Quando um artista resolve brincar com as faixas de pedestres. Pixel Show, s/d. Recuperado em 05 de outubro de 2019 de, https://zupi.pixelshow.co/quando-um-artista-resolve-brincar-com-faixasde-pedestres/

Gil, A. C.. Métodos e Técnicas de Pesquisa Social. 6. ed. São Paulo: Atlas, 2008.

Gobé, M. (2009). Emotional Branding: the new paradigm for connecting brands to people. New York: Allworth Press.

Heitner, D. (2012). Red Bull Stratos worth tens of millions of dollars in global exposure for Red Bull brand. Forbes. Recuperado em 06 de outubro de 2019 de, https://www.forbes.com/sites/ darrenheitner/2012/10/15/red-bull-stratos-worth-tens-of-millions-of-dollars-in-global-exposure-forthe-red-bull- brand/\#1e6e9bc77df5

Interbrand (2019). Best Global Brands 2019 Ranking. Recuperado em 06 de outubro de 2019 de, https://www. interbrand.com/best-brands/best-global-brands/2019/ranking/

Killing, G. E. (2017). Killing S.A. Tintas e Adesivos: Sucessão e Competência. Projeto de Preparação da $3^{a}$ Geração para Conselho de Administração. Dissertação (Mestrado) - Curso de Finanças e Governança, ESPM: Porto Alegre.

Killing S.A. (2019) Killing. Recuperado em 10 de abril de 2019 de, http://www.killing.com.br/empresa. Kotler, P., \& Keller, K. L. (2012). Administração de marketing. 14. ed. São Paulo: Pearson Education do Brasil. Kotler, P., Kartajaya, H., \& Setiawan, I. (2017) Marketing 4.O. Rio de Janeiro: Gmt Editores Ltda. 
Levitt, T. (1980) Marketing Success Through Differentiation-of Anything. Recuperado em 08 de maio de 2019 de, https://hbr.org/1980/01/marketing-success-through-differentiation-of- anything

Meadwestvaco Corporation. (2015). Packaging Matters: Second annual study ofthe role packaging plays in consumer purchasing behaviour, brand loyalty and overall product satisfaction. Recuperado em 15 de outubro de 2019 de, https:// www.webpackaging.com/en/portals/westrock/assets/11133752/mvwpackaging-matters/

Melo, G. L. de. (2019). A humanização da comunicação de marketing: interações da empresa Netflix com seus seguidores em uma rede social. Trabalho de Conclusão de Curso (Graduação em Administração) Universidade Estadual da Paraíba.

Outdoor da marca Absolut em Nova York (n.d.) Recuperado em 15 de novembro de 2019 de Flickr: https://www. flickr.com/photos/groovylab/127427534/in/photostream/

Pereira, F. dos S., \& Silva, M. F. de O. (2014). Panorama Setorial 2015-2018: Indústria Química. Recuperado em 10 de abril de 2019 de, https://web.bndes.gov.br/bib/jspui/ bitstream/1408/ 14377/1/Industria\%20quimica_P_ BD.pdf

Porter, M. E. (1985) Competitive Advantage: Creating and Sustaining Superior Performance. New York: The Free Pass.

Pulizzi, J. (2016). Marketing de Conteúdo Épico: Como contar uma história diferente, destacar-se na multidão e conquistar mais clientes com menos marketing. São Paulo: Dvs Editora.

Reiman, J. (2013). Propósito: porque ele engaja colaboradores, constrói marcas fortes e empresas poderosas. São Paulo: Hsm Editora.

Ries, A., \& Trout, J. Posicionamento: a Batalha por sua Mente. São Paulo: M. Books do Brasil Ltda., 2009.

Robbie, R. (2018). Onde encontrar faixa de pedestre colorida na Holanda. Holandesando. Recuperado em 05 de outubro de 2019 de, https://holandesando.com/ faixa-de-pedestre-colorida/

Rocha, M., \& Ignácio, S. (2017) Gestão estratégica de marcas. São Paulo: Saraiva Educação.

Superti, P. (2019). Marketing de Diferenciação. In: Fator X Live. São Paulo.

Superti, P., \& Den, D. (2019). Marketing de Diferenciação: Como aplicar marketing de diferenciação em qualquer mercado. Recuperado em 01 de outubro de 2019 de, https://www.ofatorx.com.br/wp-content/ uploads/2019/08/ebook-diferenciacao. pdf

Thompson Junior. A. A., Strickland III, A.J.,\& Gamble, J. E. (2008). Administração Estratégica 15. ed. Porto Alegre: Amgh Editora Ltda.

Troiano, J. (2016). As marcas no divã: uma análise de consumidores e criação de valor. 2. ed. São Paulo: Troiano Editora. 